Journal of Advanced Research in Fluid Mechanics and Thermal Sciences

\title{
Influence of Temperature and Velocity of Fluid on The Rate of Corrosion of Mild Steel in Existence of NPK (Nitrogen, Phosphorus, and Potassium) Inhibitor in Tap Water System
}

\author{
Abdulrazzaq Saeed Abdullah ${ }^{1,}{ }^{*}$, Akram Awad Al-Asadi ${ }^{1}$, Layla Balasem Almalike ${ }^{1}$ \\ Chemical and Petrochemical Tech. Eng. Dept, Engineering Technical College Basrah, Southern Technical University, Iraq
}

\begin{tabular}{|c|c|}
\hline ARTICLE INFO & ABSTRACT \\
\hline $\begin{array}{l}\text { Article history: } \\
\text { Received } 24 \text { October } 2019 \\
\text { Received in revised form } 22 \text { April } 2020 \\
\text { Accepted } 24 \text { April } 2020 \\
\text { Available online } 31 \text { July } 2020\end{array}$ & $\begin{array}{l}\text { The corrosion of using various concentrations of the NPK inhibitor on the mild steel in } \\
\text { the tap water was investigated at various temperatures and } 1.2 \mathrm{~m} / \mathrm{s} \text { fluid velocity. The } \\
\text { results revealed that the efficiency of NPK inhibitors relies on the temperature and the } \\
\text { concentration. The coverage ratio and efficiency increase due to the formation } \\
\text { inhibitor's layer on the metals' surface; therefore, this stops the reaction of corrosion. } \\
\text { The inhibitor's efficiency decreases for NPK concentration above } 75 \mathrm{ppm} \text { once the } \\
\text { temperature increased above } 35^{\circ} \mathrm{C} \text {. The type of adsorption is followed the Frumkin } \\
\text { model. The increase inactivate energy (Ea) at a low concentration of inhibitor maybe } \\
\text { understand as the physical adsorption. The negative value of the change in enthalpy } \\
\text { reveals the exo-thermic nature of the dissolution of mild steels. Furthermore, the } \\
\text { negative value of }\left(\Delta \mathrm{S}^{\circ}\right) \text { means increasing in disordering. }\end{array}$ \\
\hline
\end{tabular}

Keywords:

Corrosion; Inhibitor; Velocity; Adsorption

Copyright $\odot 2020$ PENERBIT AKADEMIA BARU - All rights reserved

\section{Introduction}

Generally, a corrosion process assisted by mass transfer and chemical dissolution is called a flow accelerated corrosion (FAC) and it is different from the erosion-corrosion process. From the practical way, it assumed that there is some influence from the mechanical parameter leading to the collapse of the scale on the surface of the corroded material to become unfastened and flood out with the high speed of the fluid. Such a parameter could be auxiliary increased the overall flow accelerated corrosion; however, it is not considered as a parameter for thinning by itself. The initiation of the dissolution of the electrochemical process primarily leads to FAC and the establishment of a loosely held scale [1-4].

Corrosion Inhibitors are chemicals acting to mitigate or decrease the rate of corrosion of the surfaces of mild steels. Corrosion considers as an electro-chemical process happening because of anodic reactions and/or cathodic reactions. Mostly, oxidation of the metal ions is called the anodic

\footnotetext{
* Corresponding author.

E-mail address: abdalmaliky@stu.edu.iq
}

https://doi.org/10.37934/arfmts.73.2.4655 
reaction, and reduction of the hydrogen ions is called the cathodic reaction. Thus, the inhibitions of the anodic site are the inhibitors utilized to mitigate the anodic reactions. Also, the inhibition of the cathodic site used to prevent the cathodic reactions are known as the cathodic inhibitors. Anodic Inhibitions shape a protecting layer covering on anodic site of the metals where the surface of metals is vanished and therefore straightforwardly governor the corrosion rate by inhibiting the reaction that consequences in the corrosion process. The corrosion rate of any uncovered sites on the surface of the metal will be increased as much as compared to the covered areas. Thus, such a factor might result in a localized or pitting attack of the uncovered sites on the surface of the mild steel [5].

Cathodic Inhibitors develop a protecting film covering on the cathodic metal areas of the metal where the metal's surface does not vanish. Therefore, they are indirectly mitigated the corrosion rate interfering with the flow of current needed for electrochemical reaction to progress between the anodic and cathodic metal [6].

NPK (nitrogen (10)-phosphorous (52)-potassium (10)) fertilizer is mostly comprised of three core components which are 1- Nitrogen (N), 2- Phosphorus (P), and 3- Potassium (K). Indeed, they are necessary for the nutrition of plants.

A necessary environmental parameter affecting the performance of the inhibitor via assisting the process of molecular from the bulk to the surface. Despite many researchers have conducted studies regarding the organic compounds' behavior in case of hydrodynamic and static flow, the conditions of hydrodynamic flow can influence the inhibition process such as 1-presence more inhibitor on the surface of metals due to increasing the transfer of mass of inhibitor molecules [7-21], 2- increase the transfer of mass for metal ions, which are produced by dissolution of metals, from the surface of the electrode to the bulk solution and resulting in lower [Fe-Inh] ${ }^{+2}$ complex existing on the electrode. Therefore, the performance of inhibitor is harmfully affected by such transfer of metal ions, and 3increase shear stress can separate adsorbed complex of [Fe-Inh ${ }^{+2}$ and layer of inhibitor and leads to extra desorption from the surface of the metals acting as a harmful parameter on the efficiency of the inhibitor [7-13,20-21].

In the present work, the effect of NPK as an inhibitor for carbon steel is discussed employing the method of weight loss. Adsorption entropy and adsorption enthalpy which is thermodynamic parameters were estimated from an empirical data of the process of inhibition at various temperatures and deferent concentration of the inhibitor at $1.2 \mathrm{~m} / \mathrm{s}$ velocity of the fluid. It is also determined the pre-exponential factor and the apparent activation energy in the presence of various inhibitor concentrations. Also, their influences on the rate of corrosion of carbon steel were deliberated.

\section{Experimental Setup}

To examine the influence of velocity on the corrosion rate of mild steel, the experimental setup is designed at atmospheric pressure. The experiments can perform at various temperatures (30- 45 $\left.{ }^{\circ} \mathrm{C}\right), 1.2 \mathrm{~m} / \mathrm{s}$ water velocity, and at running time 3 hours. The layout of the experimental setup is shown in Figure 1. Two coupons (1.4 cm diameter) were placed in the holder of the specimen for the analysis.

\subsection{Experimental Method}

The method adopted as follows

I. Three degrees of sandpaper $(100,220$, and 400$)$ is used to polish the samples.

II. Put both samples in Alcohol to remove impurities substance from the samples, 
III. Then dry and weight them.

IV. Put the samples in the holder.

V. Add $50 \mathrm{ppm}$ of NPK inhibitor to the water in the tank of the device then heat the water until it reaches $30^{\circ} \mathrm{C}$ for three hours then record the reading result.

VI. Repeat the same steps using different concentrations $(75,100$, and $150 \mathrm{ppm})$ with various water temperatures of 35,40 and $45^{\circ} \mathrm{C}$.

VII. At the end of each experiment, remove the sample from the holder, dry it, and clean it with rubber.

VIII. Use the Clark solution to remove the corrosion products prepared according to ASTM-G 103 guidelines [22].

IX. Record the new weight of the samples.

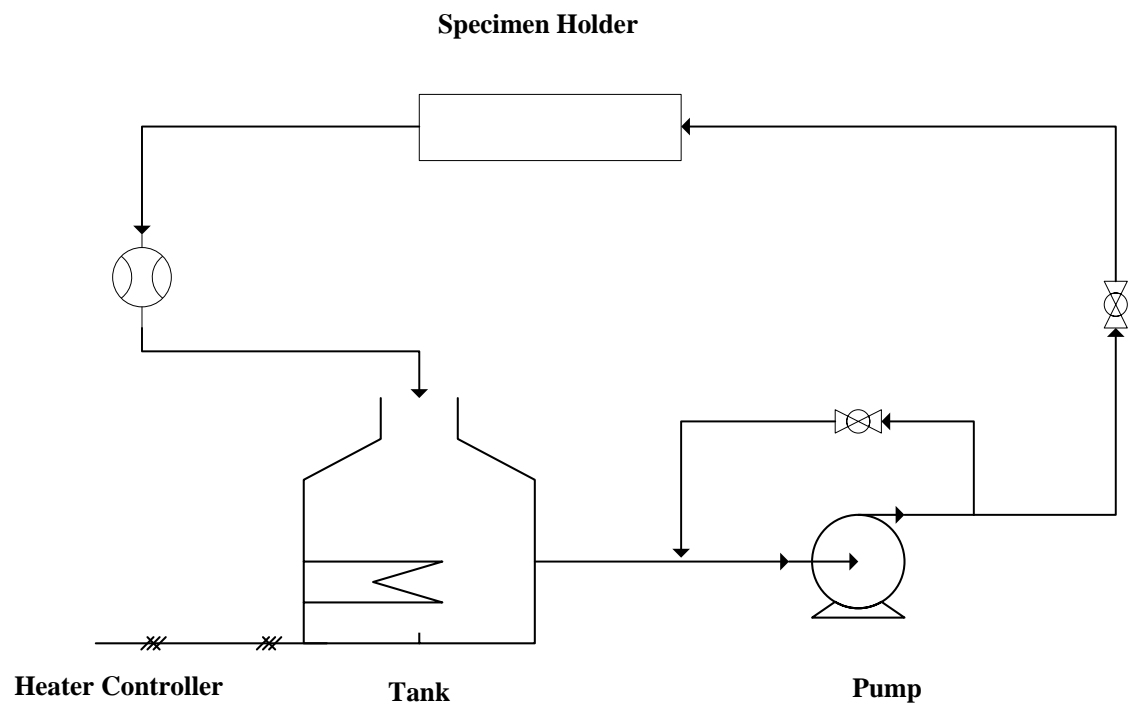

Fig. 1. Flow chart of the experimental setup

\section{Results and Discussion}

\subsection{Effect of Concentration}

The following Eq. (1)-(3) are used to calculate the rate of corrosion CR (mpy), an efficiency of inhibitor (\%IE), and surface coverage $(\Theta)$ by using weight loss method:

$\mathrm{CR}=\frac{87.6 * \Delta \mathrm{W}}{7.85 * \mathrm{~T} \times \mathrm{A}}$

$\% \mathrm{IE}=\frac{\mathrm{CRo}-\mathrm{CR} \mathrm{i}}{\mathrm{CRo}} \times 100 \%$

$\theta=\frac{\mathrm{CRo}-\mathrm{CR} \mathrm{i}}{\mathrm{CRo}}$

where $\Delta \mathrm{W}$ is the weight loss $(\mathrm{g}), \mathrm{A}$ is the surface exposed area of the sample $\left(\mathrm{cm}^{2}\right), \mathrm{T}$ is the time of immersion (hr), $\mathrm{CR}_{\circ}$ and $\mathrm{CR}_{\mathrm{i}}$ are the corrosion rate with and without inhibitor, respectively.

The experimental result showed that the efficiency NPK inhibitors depend on the temperature and the concentration. Besides, when increasing the concentration of inhibitor, the corrosion rate decreases, as shown in Figure 2. The efficiency and coverage ratio increase because of the formation 
layer of the inhibitor on the surface of metals; hence, this prevents the reaction of corrosion, as shown in Figure 3 and Figure 4.

For 30 and $35^{\circ} \mathrm{C}$ temperature, the corrosion rate decreases as increasing the concentration of inhibitor and lead to block the active sites on the metal's surface. In contrast, the corrosion rate decreases at $75 \mathrm{ppm}$ for 40 and $45^{\circ} \mathrm{C}$ and starts to slightly increase above that concentration. In the case of increasing concentration, this may attribute to exceed critical micelles concentration of the inhibitor and collapse of the corrosion inhibitor's layer in which the inhibition will not exist, and the corrosion is uncontrollable.

In the case of increasing temperature, decreasing the rate of corrosion in each NPK's concentration excluding $75 \mathrm{ppm}$ due to escaping the oxygen from the solution (open system) resulting to decrease the diffusion process, as shown in Figure $2[2,5,7]$.

The efficiency and coverage ratio of inhibitor increases with increasing temperature in each concentration from 30 and $35{ }^{\circ} \mathrm{C}$ and just below the concentration of $75 \mathrm{ppm}$ for 40 and $45{ }^{\circ} \mathrm{C}$. However, the highest and optimum efficiency is observed at $45^{\circ} \mathrm{C}$ with a concentration of $75 \mathrm{ppm}$. When the NPK's concentration is above $75 \mathrm{ppm}$, the efficiency reduces with increasing temperature. This indicates that steel's dissolution dominates adsorption of inhibitor at higher temperatures, as shown in Figure 3 and Figure 4 [15].

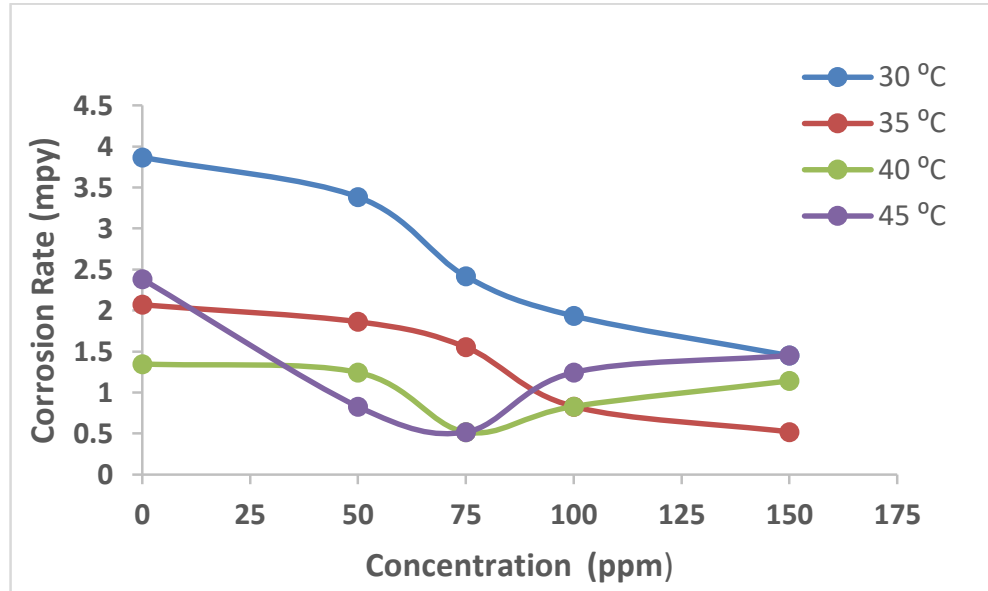

Fig. 2. The Corrosion rate at different concentrations of NPK inhibitor, temperatures at $1.2 \mathrm{~m} / \mathrm{s}$

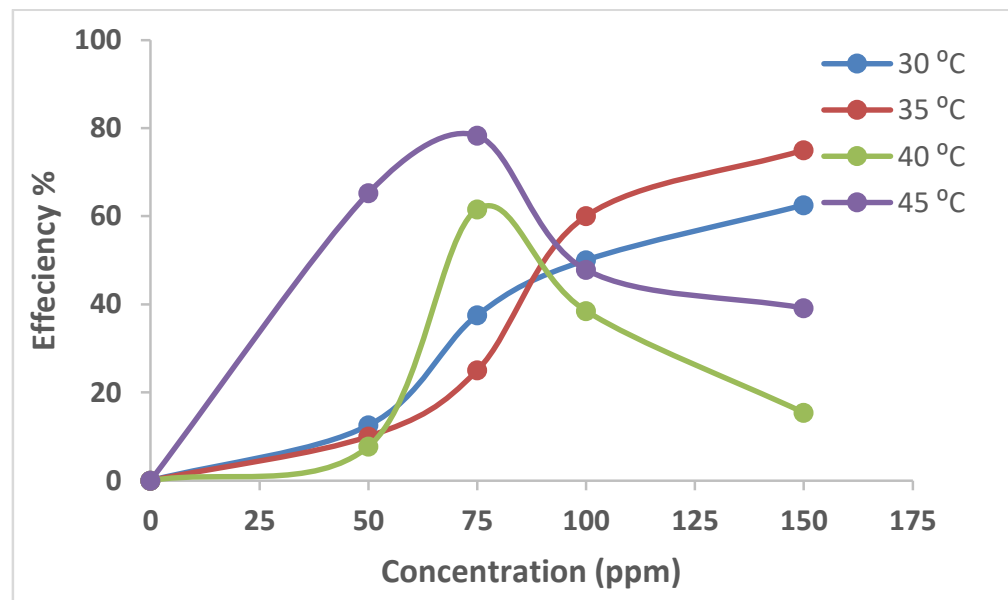

Fig. 3. The efficiency of NPK inhibitors at altered temperatures, concentrations, and at $1.2 \mathrm{~m} / \mathrm{s}$ 


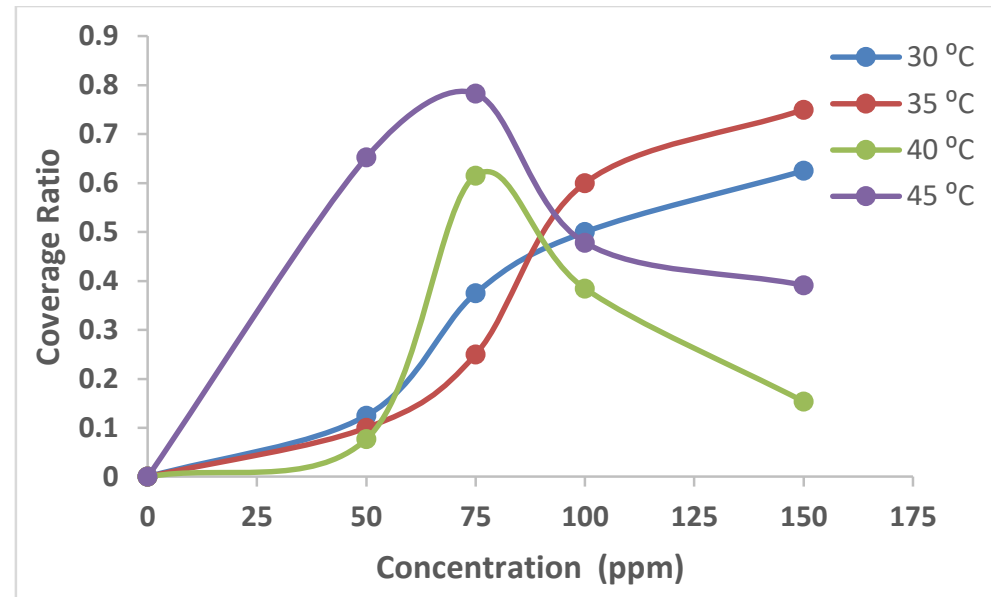

Fig. 4. The Coverage of carbon steel at different concentrations of NPK, temperatures at $1.2 \mathrm{~m} / \mathrm{s}$

\subsection{Thermodynamics Parameters}

The transition state Eq. (4) and Arrhenius Eq. (5), utilized to evaluate the thermodynamic functions of the disbanding of mild steels without and with of NPK inhibitors. The results are given in Table 1.

$\mathrm{W}=\mathrm{A} \exp \left(-\frac{\mathrm{E}_{\mathrm{a}}}{\mathrm{RT}}\right)$

$\mathrm{W}=\left(\frac{\mathrm{RT}}{\mathrm{Nh}}\right) \exp \left(\frac{\Delta \mathrm{S}^{\circ}}{\mathrm{R}}\right) \exp \left(\frac{-\Delta \mathrm{H}^{\circ}}{\mathrm{RT}}\right)$

where $\mathrm{R}$ denotes to the gas constant, Ea denotes to the appearance of the activation energy, $\mathrm{A}$ denotes a pre-exponential factor of the Arrhenius, $\mathrm{h}$ denotes constant of Planck, $\Delta \mathrm{S}^{\circ}$ denotes the change in entropy of activation, $\Delta \mathrm{H}^{\circ}$ denotes the change in enthalpy of activation, and $\mathrm{N}$ denotes the number of Avogadro's [23-24].

Table 1

The activation energies of the corrosion of mild steel

\begin{tabular}{ll}
\hline Slop $(-\mathrm{m})$ & Ea $(\mathrm{kJ} / \mathrm{mol})$ \\
\hline-0.0682 & -0.56606 \\
0.1377 & 1.14291 \\
0.2856 & 2.37048 \\
0.0412 & 0.34196 \\
-0.0503 & -0.41749 \\
\hline
\end{tabular}

The activation energy is achieved from plotting LnW versus $1 / T$ for Eq. (4), and the $\Delta S^{\circ}$, and, $\Delta H^{\circ}$ is got from plotting LnW/T versus $1 / T$ for Eq. (5). At low concentrations of inhibitor, the increase inactivate energy Ea can be understood as physical adsorption. The negative values of $\Delta \mathrm{H}^{\circ}$ reveal the exothermic nature of mild steel in the process of disbanding. The negative values $\Delta \mathrm{S}^{\circ}$ reveal an increase in disordering. The results are shown in Table 2. 
Table 2

Thermodynamic parameters of mild steals at different concentrations of NPK inhibitor

\begin{tabular}{lll}
\hline $\mathrm{C}(\mathrm{ppm})$ & $\Delta \mathrm{H} \circ(\mathrm{kJ} / \mathrm{mole})$ & $\Delta \mathrm{S}=(\mathrm{kJ} / \mathrm{mole})$ \\
\hline 0 & -33.3724 & -84.87 \\
50 & -76.7798 & -227.621 \\
75 & -94.3639 & -288.314 \\
100 & -3.45031 & 7.382174 \\
150 & 15.92131 & 68.39031 \\
\hline
\end{tabular}

\subsection{Adsorption Isotherm}

\subsubsection{Langmuir isotherm}

The model of Langmuir isotherm is effective for adsorption of the monolayer on a covering of surfaces at a limited identical place. This standard simulates unchanging energies of adsorption on the surface and there is no traveling of adsorbate in the surface's plane. Depended on the above facts, such model denoted by Eq. (6).

$\frac{\theta}{1-\theta}=\mathrm{KC}$

where $\theta$ denotes the coverage's surface, $\mathrm{C}$ denotes the concentration of inhibitors, $\mathrm{K}$ denotes the equilibrium constant of adsorption-desorption. The Langmuir model represents in Figure 5.

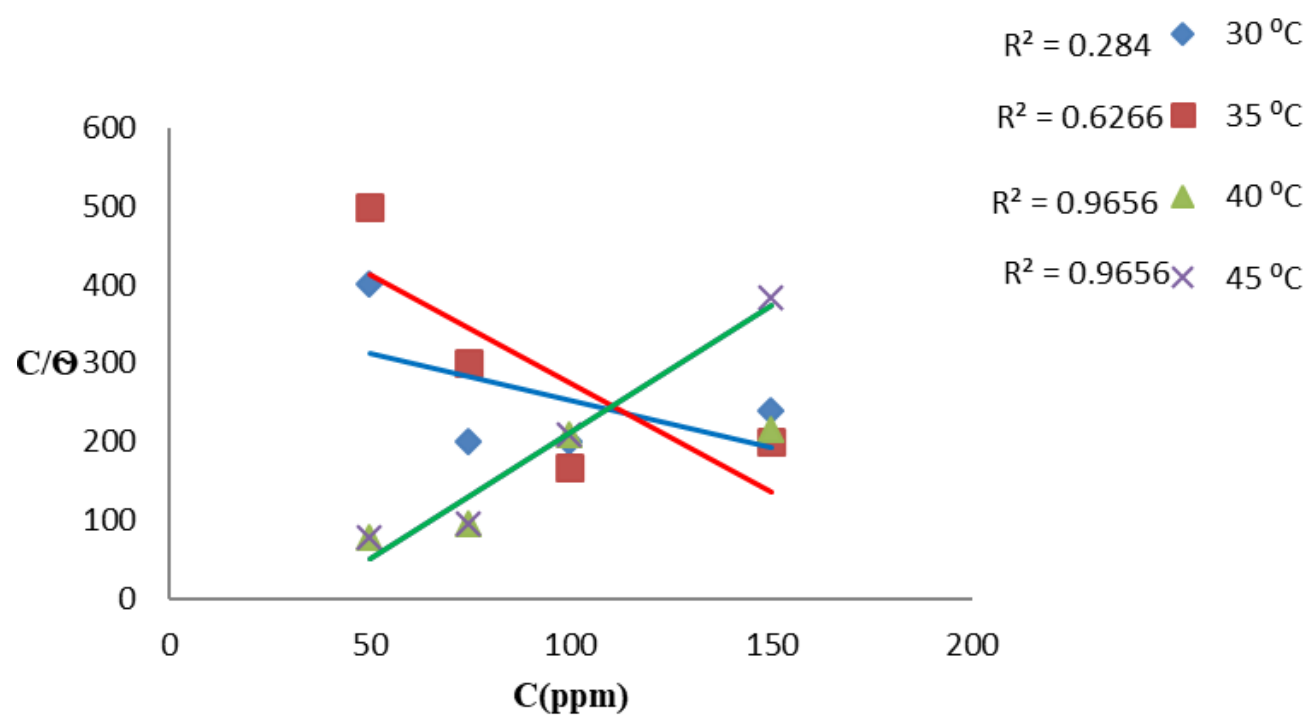

Fig. 5. Langmuir adsorption isotherm for NPK inhibitor

\subsubsection{Model of Temkin isotherm}

The model of isotherm includes parameters that taking obviously in the account of the interaction of the adsorbate-adsorbent. Disregarding a great and very low value of concentration, Temkin Isotherm supposed that the heat of adsorption (known as an occupation of temperature) of every part of molecules in the scale would reduce linearly instead of logarithmic with the coverage. It denoted by Eq. (7).

$\log \left(\frac{\theta}{C}\right)=\log K-g \theta$ 
where $\theta$ denotes the coverage's surface, $\mathrm{C}$ denotes the concentration of inhibitors, $\mathrm{K}$ the denotes constant of equilibrium of desorption- adsorption, and $g$ denotes parameter of the interaction of adsorbate. Temkin model represents in Figure 6.

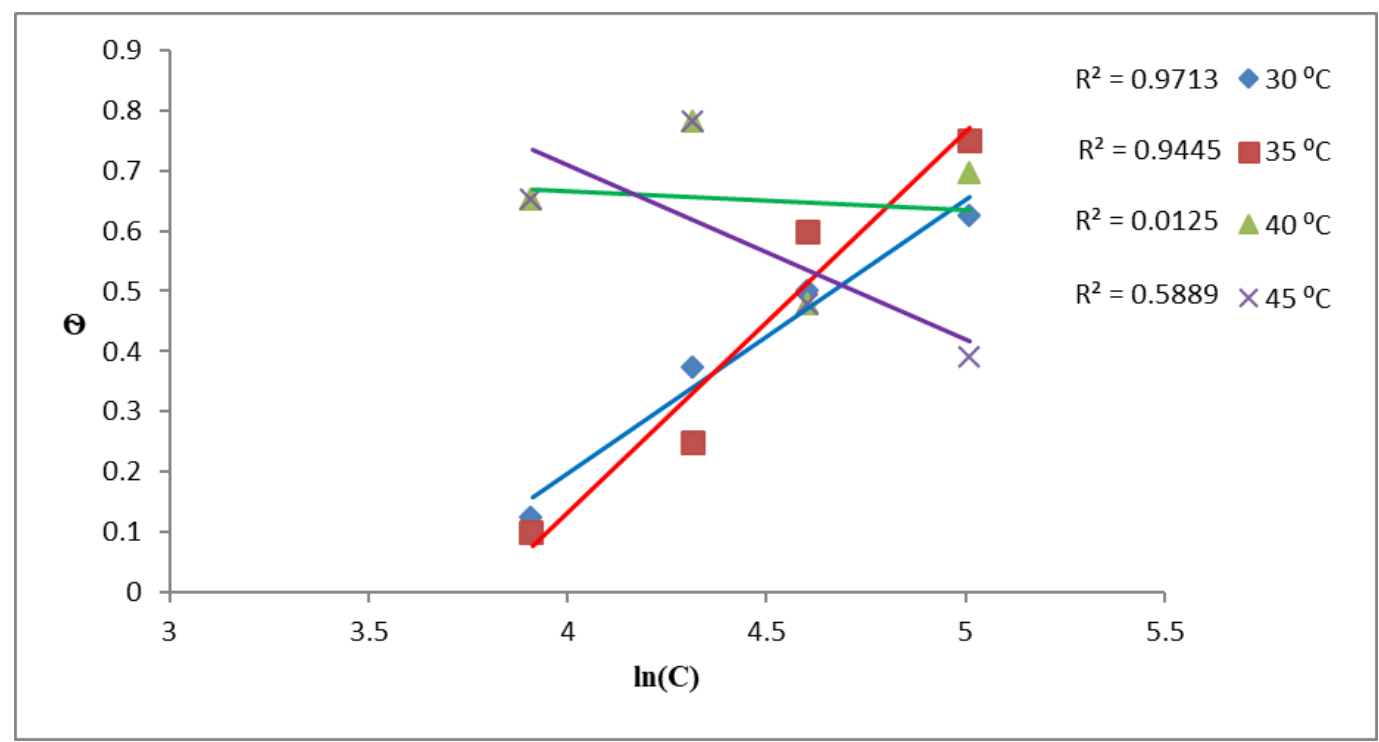

Fig. 6. Timkin adsorption isotherm for NPK inhibitor

\subsubsection{Model of Frumkin isotherm}

Such a model is generally utilized to define the features of adsorptions for the nonhomogeneous surface. It denoted in Eq. (8).

$\log \left(\frac{\theta}{(1-\theta) \mathrm{C}}\right)=\log \mathrm{K}+\mathrm{g} \theta$

where $\theta$ denotes the coverage's surface, $\mathrm{C}$ denotes the concentration of inhibitors, $\mathrm{K}$ denotes the constant of equilibrium of desorption-adsorption, and $g$ denotes the parameter of interactions of the adsorbate. The Frumkin isotherm model represents in Figure 7. The Frumkin isotherm model is considered as the best to fit the experimental data as compared with other models.

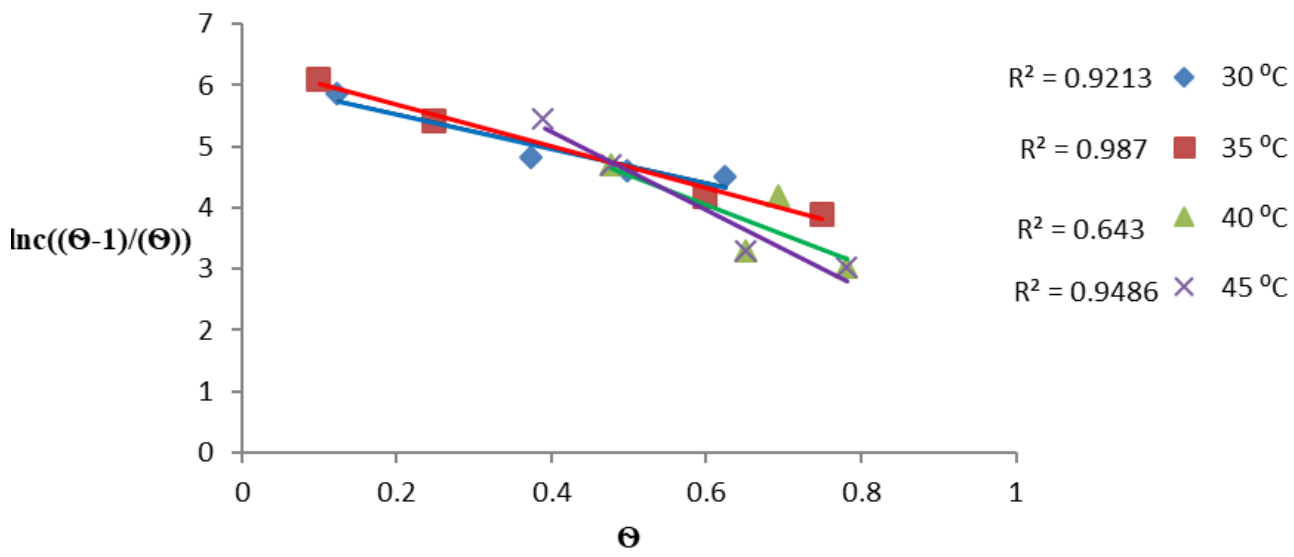

Fig. 7. Frumkin adsorption isotherm for NPK inhibitor 


\subsubsection{Model of Freundlich isotherm}

The model of Frendlich isotherm is considered as nonlinear and can be described by Eq. (9).

$\log (\theta)=\log \mathrm{K}+\mathrm{n} \log \mathrm{C}$

This model is presented the data of concentration and adsorption by plotting $\log C$ vs $\log \theta$, as shown in Figure 8. This plot will lead to a straight line with an intercept of log $\mathrm{K}$ and slop of $\mathrm{n}$. It cannot reach maximum adsorption as the linear adsorption isotherm [25].

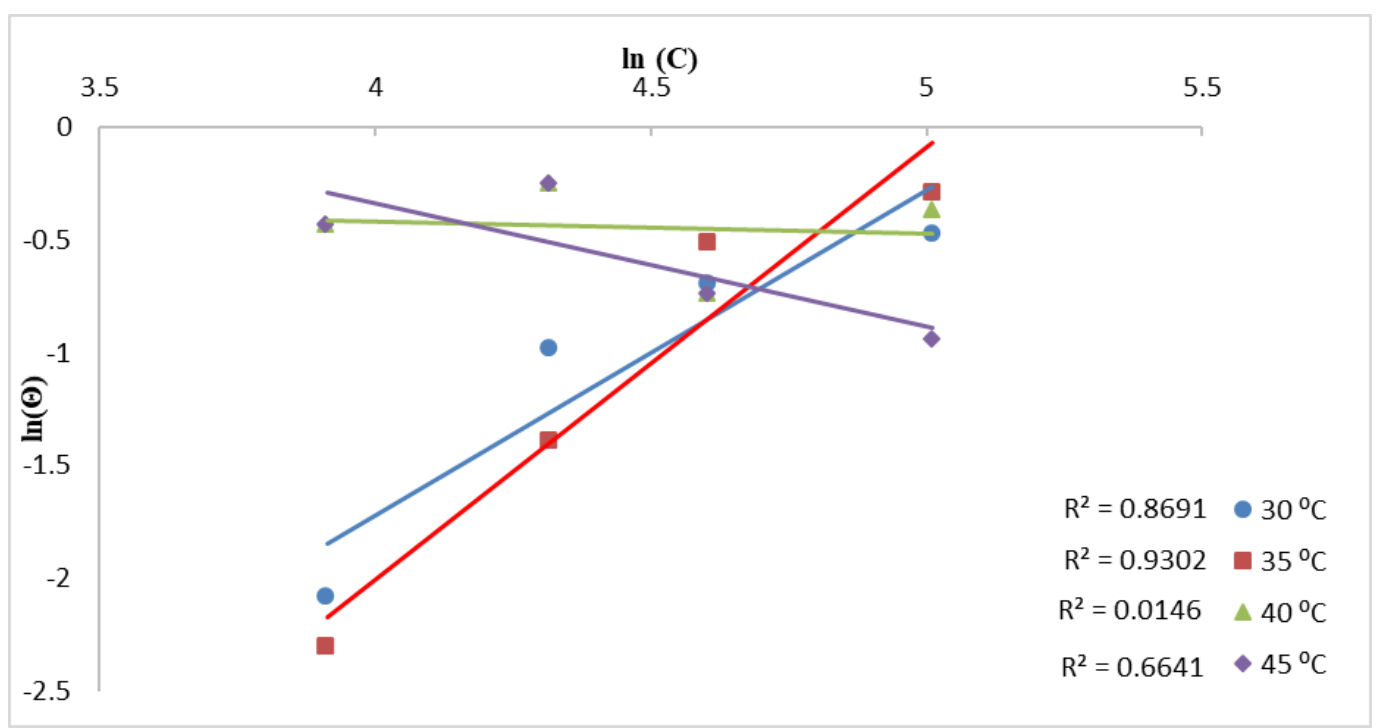

Fig. 8. Freundlich adsorption isotherm for NPK inhibitor

\section{Conclusion}

NPK performances as an efficient inhibition for the carbon steel at all examined concentrations which is below $75 \mathrm{ppm}$ and its inhibition efficiency exceeds $78 \%$ at $45^{\circ} \mathrm{C}$ and $75 \mathrm{ppm}$. The reduction in corrosion rate is observed with increasing temperature excluding above $75 \mathrm{ppm}$. The efficiency reduces along with increasing temperature above $75 \mathrm{ppm}$. The thermodynamic parameters indicated that NPK inhibitor is caused a physical adsorption and its adsorption obeys to the Frumkin's adsorption isotherm. The negative value of $(\Delta \mathrm{H}$ o $)$ imitates the exothermic nature of the dissolution of mild steels. Besides, the negative value of $(\Delta \mathrm{S}-)$ means increasing in disordering.

\section{References}

[1] Muhammadu, Muhammadu Masin, Jamaluddin Sheriff, and Esah Hamzah. "Review of literature for the flow accelerated corrosion of mitred bends." International Journal of Emerging Technology and Advanced Engineering 8, no. 3 (2013): 663-677.

[2] Al-Asadi, Akram A. "Iron Carbide Development and its Effect on Inhibitor Performance." PhD diss., Ohio University, 2014.

[3] Omar, Nooririnah, Suhana Mohamed, Raja Zuraidah Raja Rasi, and Aminah Ahmad. "Effect of cold sprayed Al coating on corrosion behaviour of sponson spar." Journal of Advanced Research in Materials Science 28, no. 1 (2017): 1-18.

[4] Hong, W. X., NA Che Sidik, and M. Beriache. "Heat transfer performance of hybrid nanofluid as nanocoolant in automobile radiator system." Journal of Advanced Research Design 51, no.1 (2018): 14-25. 
[5] Al-Asadi, Akram A., Abdulrazzaq S. Abdullah, Narjes I. Khaled, and Raad JM Alkhafaja. "Effect of an Aloe Vera As a Natural Inhibitor on The Corrosion of Mild Steel in 1 wt.\% NaCl." International Research Journal of Engineering and Technology 2, no. 6 (2015): 604-607.

[6] Raheem, Dina. "Effect of mixed corrosion inhibitors in cooling water system." Al-Khwarizmi Engineering Journal 7 , no. 4 (2011): 76-87.

[7] Badiea, A. M., and K. N. Mohana. "Effect of temperature and fluid velocity on corrosion mechanism of low carbon steel in presence of 2-hydrazino-4, 7-dimethylbenzothiazole in industrial water medium." Corrosion Science 51, no. 9 (2009): 2231-2241.

https://doi.org/10.1016/i.corsci.2009.06.011

[8] Douadi, Tahar, Hanane Hamani, Djamel Daoud, Mousa Al-Noaimi, and Salah Chafaa. "Effect of temperature and hydrodynamic conditions on corrosion inhibition of an azomethine compounds for mild steel in $1 \mathrm{M} \mathrm{HCl}$ solution." Journal of the Taiwan Institute of Chemical Engineers 71 (2017): 388-404. https://doi.org/10.1016/j.jtice.2016.11.026

[9] Hasan, Basim O., and Sara A. Sadek. "The effect of temperature and hydrodynamics on carbon steel corrosion and its inhibition in oxygenated acid-salt solution." Journal of Industrial and Engineering Chemistry 20, no. 1 (2014): 297-307.

https://doi.org/10.1016/i.jiec.2013.03.034

[10] Lopes-Sesenes, R., G. F. Dominguez-Patiño, J. G. Gonzalez-Rodriguez, and J. Uruchurtu-Chavarin. "Effect of flowing conditions on the corrosion inhibition of carbon steel by extract of buddleia perfoliata." Int. J. Electrochem. Sci 8 (2013): 477-489. https://doi.org/10.5599/jese.2012.0013

[11] Soosaiprakasam, Immanuel Raj, and Amornvadee Veawab. "Corrosion inhibition performance of copper carbonate in MEA-CO2 capture unit." Energy Procedia 1, no. 1 (2009): 225-229.

https://doi.org/10.1016/i.egypro.2009.01.032

[12] Saremi, M., N. Parsi Benehkohal, C. Dehghanian, and H. R. Zebardast. "Effect of calcium gluconate concentration and hydrodynamic effect on mild steel corrosion inhibition in simulated cooling water." Corrosion 65, no. 12 (2009): 778-784. https://doi.org/10.5006/1.3319104

[13] Kosari, Ali, Mohammad Hadi Moayed, Ali Davoodi, Reza Parvizi, Mojtaba Momeni, Hossein Eshghi, and Hassanali Moradi. "Electrochemical and quantum chemical assessment of two organic compounds from pyridine derivatives as corrosion inhibitors for mild steel in $\mathrm{HCl}$ solution under stagnant condition and hydrodynamic flow." Corrosion Science 78 (2014): 138-150. https://doi.org/10.1016/i.corsci.2013.09.009

[14] Saremi, M., C. Dehghanian, and M. Mohammadi Sabet. "The effect of molybdate concentration and hydrodynamic effect on mild steel corrosion inhibition in simulated cooling water." Corrosion Science 48, no. 6 (2006): 1404-1412. https://doi.org/10.1016/i.corsci.2005.06.009

[15] Touir, R., N. Dkhireche, M. Ebn Touhami, M. Sfaira, O. Senhaji, J. J. Robin, B. Boutevin, and M. Cherkaoui. "Study of phosphonate addition and hydrodynamic conditions on ordinary steel corrosion inhibition in simulated cooling water." Materials Chemistry and Physics 122, no. 1 (2010): 1-9. https://doi.org/10.1016/i.matchemphys.2010.02.063

[16] Aljourani, J., K. Raeissi, and M. A. Golozar. "Benzimidazole and its derivatives as corrosion inhibitors for mild steel in $1 \mathrm{M} \mathrm{HCl}$ solution." Corrosion science 51, no. 8 (2009): 1836-1843.

https://doi.org/10.1016/i.corsci.2009.05.011

[17] Daoud, Djamel, Tahar Douadi, Hanane Hamani, Salah Chafaa, and Mousa Al-Noaimi. "Corrosion inhibition of mild steel by two new S-heterocyclic compounds in $1 \mathrm{M} \mathrm{HCl}$ : experimental and computational study." Corrosion Science 94 (2015): 21-37. https://doi.org/10.1016/j.corsci.2015.01.025

[18] Hamani, Hanane, Tahar Douadi, Mousa Al-Noaimi, Saifi Issaadi, Djamel Daoud, and Salah Chafaa. "Electrochemical and quantum chemical studies of some azomethine compounds as corrosion inhibitors for mild steel in $1 \mathrm{M}$ hydrochloric acid." Corrosion science 88 (2014): 234-245.

https://doi.org/10.1016/i.corsci.2014.07.044

[19] Popova, A., E. Sokolova, S. Raicheva, and Mz Christov. "AC and DC study of the temperature effect on mild steel corrosion in acid media in the presence of benzimidazole derivatives." Corrosion science 45, no. 1 (2003): 33-58. https://doi.org/10.1016/S0010-938X(02)00072-0

[20] Jiang, X., Y. G. Zheng, and W. Ke. "Effect of flow velocity and entrained sand on inhibition performances of two inhibitors for CO2 corrosion of N80 steel in 3\% NaCl solution." Corrosion science 47, no. 11 (2005): 2636-2658. https://doi.org/10.1016/i.corsci.2004.11.012 
[21] Aljourani, J., K. Raeissi, and M. A. Golozar. "Benzimidazole and its derivatives as corrosion inhibitors for mild steel in $1 \mathrm{M} \mathrm{HCl}$ solution." Corrosion science 51 , no. 8 (2009): 1836-1843. https://doi.org/10.1016/i.corsci.2009.05.011

[22] ASTM, G1. "Standard practice for preparing, cleaning, and evaluating corrosion test specimens." In American Society for Testing and Materials. 2003.

[23] Chexal, B., J. Horowitz, and B. Dooley. Flow-accelerated corrosion in power plants. Revision 1. No. EPRI-TR--106611R1. Electric Power Research Inst., 1998.

[24] Satoh, T., Y. Shao, W. G. Cook, D. H. Lister, and Shunsuke Uchida. "Flow-assisted corrosion of carbon steel under neutral water conditions." Corrosion 63, no. 8 (2007): 770-780. https://doi.org/10.5006/1.3278426

[25] Goldberg, Sabine, Louise J. Criscenti, David R. Turner, James A. Davis, and Kirk J. Cantrell. "Adsorption-desorption processes in subsurface reactive transport modeling." Vadose Zone Journal 6, no. 3 (2007): 407-435. https://doi.org/10.2136/vzj2006.0085 